\title{
The impact of a barrier enclosure on time to tracheal intubation: a randomized controlled trial
}

\section{L'impact d'une boîte de protection sur le temps d'intubation endotrachéale : une étude randomisée contrôlée}

\author{
Tim T. H. Jen, MD, FRCPC (D) - Vionarica Gusti, MD - Charanjit Badh, MD, FRCPC • \\ Sachin Mehta, MBChB, MRCP, FRCA, FFICM - Justine Denomme, MD, FRCPC • \\ Shannon Lockhart, MD, FRCPC • Benajir Shams, MSc $\cdot$ Beau Klaibert, MBChB, \\ FANZCA, FRCPC $\cdot$ Anthony Chau, MD, FRCPC, MMSc
}

Received: 19 March 2021 / Revised: 12 April 2021/Accepted: 14 April 2021/Published online: 10 May 2021

(C) Canadian Anesthesiologists' Society 2021

\begin{abstract}
Purpose Novel devices such as the barrier enclosure were developed in hopes of improving provider safety by limiting SARS-CoV-2 transmission during tracheal intubation. Nevertheless, concerns arose regarding a lack of rigorous efficacy and safety data for these devices. We conducted a randomized controlled trial to evaluate the
\end{abstract}

Supplementary Information The online version contains supplementary material available at https://doi.org/10.1007/s12630021-02024-z.

T. T. H. Jen, MD, FRCPC ( $)$ · C. Badh, MD, FRCPC . S. Mehta, MBChB, MRCP, FRCA, FFICM - J. Denomme, MD, FRCPC - S. Lockhart, MD, FRCPC - A. Chau, MD, FRCPC, MMSc

Department of Anesthesia, St. Paul's Hospital/Providence Health Care, 1081 Burrard St, Vancouver, BC V6Z 1Y6, Canada

e-mail: timothy929@gmail.com

Department of Anesthesiology, Pharmacology and Therapeutics, University of British Columbia, Vancouver, BC, Canada

V. Gusti, MD

Faculty of Medicine, University of British Columbia,

Vancouver, BC, Canada

B. Shams, MSc

Department of Anesthesia, St. Paul's Hospital/Providence Health Care, 1081 Burrard St, Vancouver, BC V6Z 1Y6, Canada

B. Klaibert, MBChB, FANZCA, FRCPC

Department of Anesthesiology, Pharmacology and Therapeutics,

University of British Columbia, Vancouver, BC, Canada

Department of Anesthesia, Vancouver General Hospital/

Vancouver Coastal Health, Vancouver, BC, Canada impact of the barrier enclosure on time to tracheal intubation.

Method After Research Ethics Board approval, elective surgical patients with normal airway predictors were randomly allocated 1:1 to tracheal intubation with or without a barrier enclosure. The primary outcome was time to tracheal intubation. Secondary outcomes included firstpass success rate, total time of airway manipulation, anesthesiologists' perception of intubation difficulty, likelihood of use in SARS-CoV-2-positive patients, and patients' perception of comfort and acceptability.

Results There were 48 participants in the barrier enclosure group and 46 participants in the control group. The mean (standard deviation [SD]) time to tracheal intubation was 62 (29) sec with barrier closure and 53 (27) sec without barrier enclosure (mean difference, 9 sec; $95 \%$ confidence interval, -3 to $20 ; P=0.14$ ). Anesthesiologists rated the difficulty of intubation higher with barrier enclosure (mean [SD] visual analogue scale score, 27 [26] $\mathrm{mm}$ vs 9 [17] $\mathrm{mm} ; P<0.001)$. There were no significant differences in other secondary outcomes.

Conclusion In healthy surgical patients with normal airway predictors, the use of a barrier enclosure during tracheal intubation did not significantly prolong time to intubation or decrease first-pass intubation success. Nevertheless, there was an increase in difficulty of intubation perceived by the anesthesiologists with use of a barrier enclosure.

Trial registration $w w w . c l i n i c a l t r i a l s . g o v(N C T 04366141)$; registered 28 April 2020. 


\section{Résumé}

Objectif De nouveaux dispositifs tels que des bottes de protection ont été mis au point dans l'espoir d'améliorer la sécurité des fournisseurs de soins en limitant la transmission du SRAS-CoV-2 pendant l'intubation endotrachéale. Néanmoins, des inquiétudes ont été soulevées au sujet d'un manque de données rigoureuses sur l'efficacité et l'innocuité de ces dispositifs. Nous avons réalisé une étude randomisée contrôlée afin d'évaluer l'impact d'une boite de protection sur le temps de l'intubation endotrachéale.

Méthode Après avoir reçu l'approbation du Comité d'éthique de la recherche, des patients de chirurgie élective présentant des prédicteurs des voies aériennes normales ont été aléatoirement répartis à un ratio de 1:1 pour une intubation endotrachéale avec ou sans botte de protection. Le critère d'évaluation principal était le temps nécessaire à l'intubation endotrachéale. Les critères d'évaluation secondaires comprenaient le taux de réussite à la première tentative, le temps total de manipulation des voies aériennes, la perception par les anesthésiologistes de la difficulté d'intubation, la probabilitéd'utilisation chez les patients atteints du SRAS-CoV-2, et la perception de confort et d'acceptabilité des patients.

Résultats Il y avait 48 participants dans le groupe avec boite et 46 participants dans le groupe témoin. Le temps moyen (écart type [ÉT]) pour l'intubation endotrachéale était de 62 (29) sec avec la boite et de 53 (27) sec sans la boite (différence moyenne, 9 sec; intervalle de confiance de $95 \%,-3$ à 20; $P=0,14)$. Les anesthésiologistes ont estimé que la difficulté d'intubation était plus élevée avec une boite de protection (score moyen sur l'échelle visuelle analogique [ÉT], 27 [26] $\mathrm{mm}$ vs 9 [17] $\mathrm{mm} ; \mathrm{P}<0,001$ ). Il $n$ 'y avait pas de différences pour les autres critères d'évaluation secondaires.

Conclusion Chez les patients chirurgicaux en bonne santé avec des prédicteurs de voies aériennes normales, l'utilisation d'une boite de protection pendant l'intubation endotrachéale n'a pas prolongé de manière significative le temps d'intubation ni réduit le taux de réussite de l'intubation à la première tentative. Néanmoins, il y avait une augmentation de la difficulté d'intubation perçue par les anesthésiologistes avec l'utilisation d'une boute de protection.

\section{Enregistrement de l'étude www.clinicaltrials.gov} (NCT04366141); enregistrée le 28 avril 2020.

Keywords COVID-19 - intubation · barrier box · barrier enclosure . personal protective equipment

The COVID-19 pandemic has resulted in over 3 million deaths as of April 2021, ${ }^{1}$ and SARS-CoV-2 transmission has been shown to occur primarily via droplets and aerosols. ${ }^{2,3}$ Consequently, providers who perform aerosolgenerating medical procedures (AGMP), such as tracheal intubation, are considered to be at high risk for viral exposure. ${ }^{4,5}$ During the early phase of the pandemic, there were concerns about the availability and adequacy of personal protective equipment (PPE) worldwide. These prompted an unmet clinical need for novel solutions that could be developed and implemented quickly to improve the anxiety and safety of providers who perform tracheal intubations. $^{6}$

One proposed solution that gained widespread popularity and attention on social media and in scientific literature was the application of a barrier enclosure during tracheal intubation. ${ }^{7,8}$ Despite the lack of rigorous efficacy and safety data on its ability to protect the intubating provider against droplets and aerosols, there was enthusiasm to adopt its clinical application and further its engineering. Airway experts have expressed concerns that the application of a barrier enclosure during intubation may result in poor ergonomics leading to prolonged time to intubation and compromising patient safety. Although mannequin studies have shown that the use of a barrier enclosure results in significantly longer time to successful intubation, ${ }^{9,10}$ this has not been validated in a clinical setting.

To bridge this data gap, we sought to determine the impact of barrier enclosure application on tracheal intubation. We hypothesized that in patients undergoing elective surgery without known or predicted difficult airways, the use of a barrier enclosure would prolong the time to successful tracheal intubation.

\section{Methods}

This study received Research Ethics Board approval (University of British Columbia Providence Health Care Research Ethics Board; \# H20-01270; 1 May 2020) and was pre-registered with Clinicaltrials.gov (NCT04366141). This manuscript adheres to the consolidated standards of reporting trials (CONSORT) guidelines.

Following written informed consent, American Society of Anesthesiologists Physical Status class I or II adults (18 $\mathrm{yr}$ of age or older) scheduled for elective non-cardiac surgery requiring orotracheal intubation were recruited between 5 May 2020 and 10 December 2020 at St. Paul's Hospital and Mount Saint Joseph's Hospital, Providence Health Care, Vancouver, British Columbia, Canada. All study patients had to complete a COVID-19 symptoms screening questionnaire that showed the absence of any of the following symptoms: fever, cough, shortness of breath, headache, runny nose/nasal congestion, loss of sense of 
smell, sore throat or painful swallowing, loss of appetite, nausea and/or vomiting, diarrhea, muscle aches, fatigue, or chills. If a preoperative COVID-19 test was performed, a negative result was required. Patients were excluded if they refused to participate or were unable to consent or cooperate; had claustrophobia or body habitus that prevented them from fitting into the barrier enclosure; had a history of documented difficult airway; had risk factors for difficult airway (i.e., Mallampati view 3 or 4 , thyromental distance less than $6 \mathrm{~cm}$, inter-incisor distance less than $4 \mathrm{~cm}$, upper lip bite test 2 or 3 , body mass index $35 \mathrm{~kg} \cdot \mathrm{m}^{-2}$ or above, macroglossia, airway edema, blood in airway, cervical immobility, or any other concerning features identified by the attending anesthesiologist) ${ }^{11,12}$; had a high risk of gastric aspiration; or had allergy to any study medications. Withdrawal criteria were excessive patient anxiety, equipment malfunction, protocol violation, unanticipated difficult airway as determined by the attending anesthesiologist, or withdrawal at the discretion of the attending anesthesiologist.

Microsoft Excel 2010 (Microsoft Inc., Redmond, WA, USA) was used to generate a randomization sequence with 1:1 allocation to either barrier enclosure or control groups. Allocation was concealed in sealed opaque envelopes that were opened following patient informed consent and enrolment. Further blinding of the study was not feasible because of the nature of the intervention and the methodology of the study.

The barrier enclosure was designed by a not-for-profit group and details of the device were non-proprietary, opensource, and shared on www.covidbox.ca. (eFigs 1 and 2; Electronic Supplementary Material). The sterilization procedure was approved by the ethics committee and local medical device reprocessing department at St. Paul's Hospital, Providence Health Care. Specifically, the enclosure was sterilized between uses and at the end of the day by dedicated operating room cleaning staff using VIREX Ii 256 One-Step Disinfectant Cleaner and Deodorant (Diversey Inc., Charlotte, NC, USA). This product fulfills Health Canada's requirements for use against emerging viral pathogens including SARS-CoV-2.$^{13}$

The intubating providers in this study were consultant anesthesiologists who had performed at least five prior intubations using the McGrath MAC videolaryngoscope (Medtronic, Minneapolis, MN, USA) ${ }^{14-16}$ and at least five prior intubations with the local COVID-19 standard operating room policies and procedures. These included the appropriate donning of PPE and waiting for the required number of operating room air exchanges after each AGMP before allowing additional personnel to enter or exit the room. In addition, all study anesthesiologists had performed at least one intubation on a mannequin with the barrier enclosure.
In the operating room, the barrier enclosure was positioned after all standard monitoring was applied. Preoxygenation was performed for five minutes prior to induction or until end-tidal oxygen concentration $\geq 80 \%$ was reached. The pharmacologic agents and doses used for induction of anesthesia were not standardized, but all the patients received rocuronium $1.2 \mathrm{mg} \cdot \mathrm{kg}^{-1}$ (based on ideal body weight). ${ }^{17}$ No bag mask ventilation was performed unless deemed necessary by the anesthesiologist. A tightfitting face mask seal was maintained for 1 minute after rocuronium administration. Laryngoscopy was performed with McGrath MAC videolaryngoscope with the blade size chosen by the anesthesiologist (McGrath MAC 3 or 4). At any point during the study period, the anesthesiologist could choose to remove the barrier enclosure and perform subsequent airway management at their own discretion. Immediately after intubation, the circuit could be attached in the front of the barrier enclosure, and it was not necessary to remove the enclosure to permit connection. A trained observer blinded to the outcome and analysis recorded all the time and outcome data. The timer was started when the face mask was applied on the patient for preoxygenation and stopped upon successful intubation. Once surgery was underway, the anesthesiologists were asked to rate the intubation difficulty and likelihood of using the barrier enclosure on SARS-CoV-2-positive patients, and to provide optional comments. The patients were asked to rate the acceptability and comfort while they were recovering in the post-anesthetic care unit.

The primary outcome was time to tracheal intubation (TTI), defined as the time from the laryngoscope blade passing between the lips until the first upstroke of the capnograph trace. Secondary outcomes included proportion of first-pass successful intubation (a failed attempt was defined as the need for the McGrath MAC video laryngoscope blade or tracheal tube to be withdrawn from the mouth, or if the first pass took longer than 150 $\mathrm{sec})^{18}$; total time of airway manipulation (defined as time from lifting of face mask seal to first upstroke of capnograph trace); anesthesiologists' perception of intubation difficulty on a $100-\mathrm{mm}$ visual analogue scale (VAS); anesthesiologists' perception of the likelihood of using a barrier enclosure on SARS-CoV-2-positive patients on a five-point Likert scale ( $1=$ very likely, $2=$ likely, $3=$ neutral, $4=$ unlikely, $5=$ very unlikely); patients' comfort on a five-point Likert scale ( $1=$ completely comfortable, 2 = comfortable, $3=$ neutral, $4=$ uncomfortable, $5=$ completely uncomfortable); and patients' acceptability on a five-point scale $(1=$ completely acceptable, $2=$ acceptable, $3=$ neutral, $4=$ unacceptable, $5=$ completely unacceptable).

A prior study by Jones et al. ${ }^{18}$ considered a betweengroup difference of ten seconds in TTI to be clinically 
significant. Using a two-sample $t$ test, a type I error of 0.05 , and standard deviation (SD) data from Yao et al., ${ }^{19}$ who found that the mean (SD) duration of intubation using the McGrath blade was 39.7 (10.5) sec, a total of 41 patients in each group would have $99 \%$ power to detect a ten-second difference in TTI between groups. To account for $20 \%$ attrition, we increased the sample size to 50 per group for a total of 100 patients.

Data for primary outcome, total time of airway manipulation, and anesthesiologists' perception of intubation difficulty were analyzed using two-sample, unpaired $t$ tests. The proportion of first-pass success rate was compared using Fisher's exact test. Anesthesiologists' perceptions of likelihood of using a barrier enclosure in actual clinical practice was compared using the Wilcoxon rank-sum test. Descriptive statistics were used for patients' comfort and acceptability ratings. We considered $P<0.05$ statistically significant. Statistical analysis was performed using R version 3.4.1 (The R Foundation for Statistical Computing, Vienna, Austria).

\section{Results}

A total of 803 patients were assessed for eligibility between 5 May 2020 and 10 December 2020, of which 703 were excluded and 100 patients were randomly allocated 1:1 to each group. One patient in the study group and four patients in the control group were excluded because of a change in operating room schedule after randomization. One patient was excluded because of protocol violation in the study group. A total of 48 patients in the intervention and 46 patients in the control groups completed the study. Fig. 1 shows the CONSORT diagram of the study.

A total of 35 anesthesiologists participated in this study. Patient and anesthesiologist characteristics are shown in Table 1. Intraoperative variables are summarized in Table 2.

The mean (SD) TTI was 62 (29) sec and 53 (27) sec in the barrier enclosure and control groups, respectively, with no significant difference between groups (mean difference [MD], 9 sec; 95\% CI, 3 to 20; $P=0.14$ ) (Fig. 2).

The proportions of patients with first-pass successful intubation were similar between groups. However, two patients required removal of the barrier enclosure during intubation because of intubation difficulty. There were no differences in the total time of airway manipulation between groups. Among patients intubated with the barrier enclosure, the anesthesiologists' mean (SD) rating in difficulty of intubation on a 100-mm VAS was significantly higher $(27$ [26] $\mathrm{mm}$ vs 9 [17] $\mathrm{mm}, P<$ 0.001) (Fig. 3). Despite this difference, anesthesiologists' perception of likelihood of using the barrier enclosure in actual clinical practice were similar between groups. Most patients found the use of the barrier box to be completely comfortable and completely acceptable (Table 3).

A total of 30 optional comments were collected by anesthesiologists who intubated with the barrier enclosure; $4 / 30$ were positive comments indicating the ease of use and less of an impediment than anticipated while $26 / 30$ were negative comments. The negative feedback included awkward ergonomics for patients (i.e., bumping on head and squishing arm) and nurse assisting with the intubation; the need for additional mental capacity during intubation; and restricted movement affecting airway maneuvers such as head repositioning and chin lifts.

\section{Discussion}

In this prospective randomized study, we found that application of a barrier enclosure during tracheal intubation by consultant anesthesiologists with the McGrath MAC videolaryngoscope did not significantly prolong TTI or decrease first-pass intubation success in elective surgical patients without known or suspected difficult airways. Nevertheless, the anesthesiologists perceived a significant increase in difficulty of intubation when a barrier enclosure was used. This difficulty may potentially be magnified when used in non-elective situations or in patients with challenging airways.

Two previous trials have evaluated the use of a barrier enclosure in a clinical setting. ${ }^{20,21}$ Trujillo and Arango found that in children over one year of age without anticipated difficult airways, the use of the barrier enclosure increased the time to intubation by a consultant anesthesiologist by a median of five seconds. ${ }^{20}$ Madabhushi et al. also found that a barrier enclosure increased the time to intubation by an experienced anesthesiologist by a mean of $10.1 \mathrm{sec}$ in adults without anticipated difficult airway; however, they used $15 \mathrm{sec}$ as a non-inferiority margin and thus did not reject the null hypothesis and concluded no difference between groups. ${ }^{21}$ Consistent with both of these studies, we found that using barrier enclosure when intubating patients with normal airways resulted in a longer mean TTI compared with control, although this effect size (mean duration of $8.6 \mathrm{sec}$ ) was neither statistically nor clinically significant. Our study finding was not surprising because the consultant anesthesiologists were likely able to compensate for any additional challenge posed by a physical barrier during intubation. As such, the result of our primary outcome cannot be generalized to a high-risk population; however, the higher difficulty in intubation due to the barrier enclosure reported by the anesthesiologists may provide some external validity. 
Fig. 1 CONSORT diagram of patient recruitment

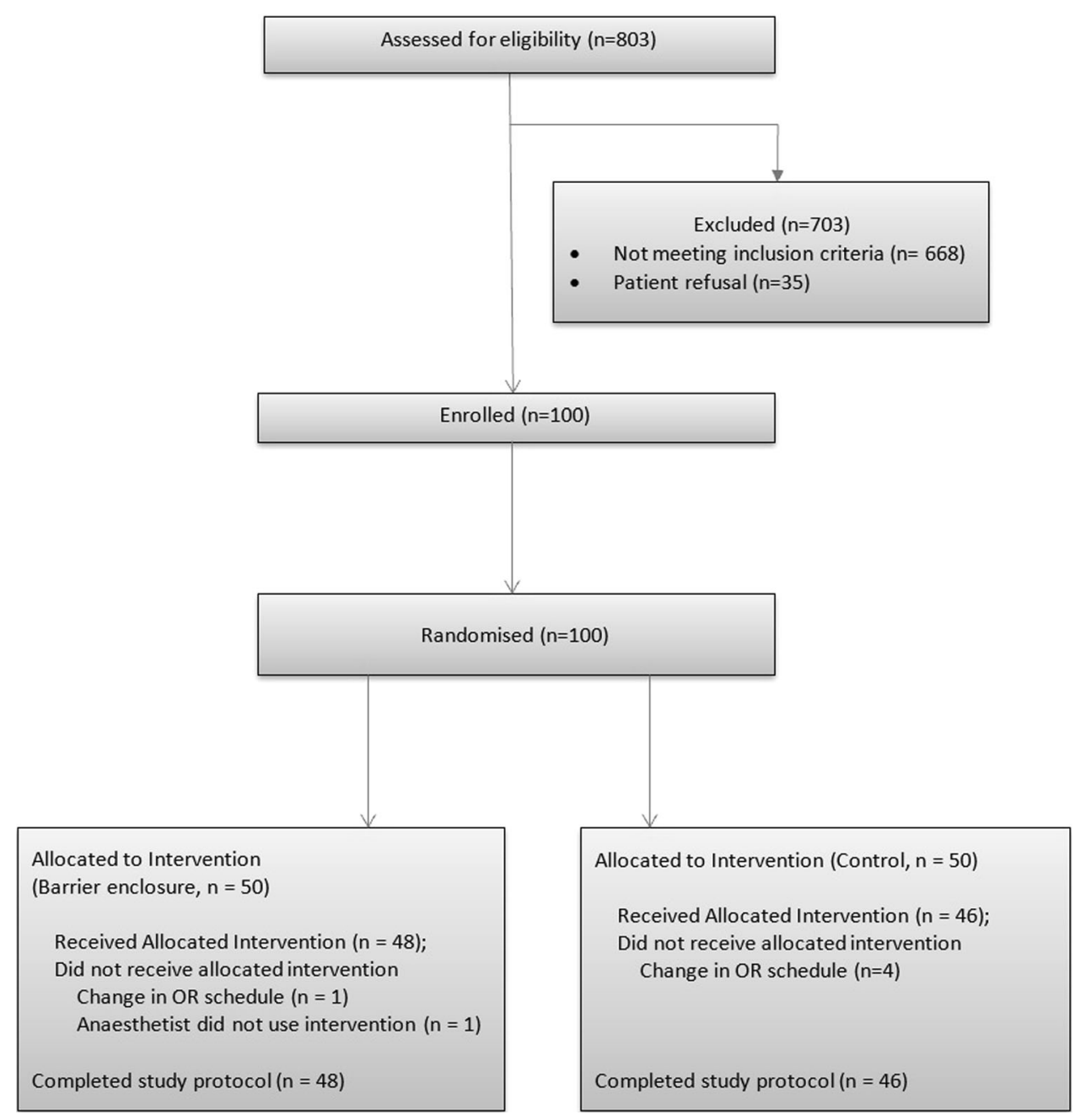

The VAS score has been used in various studies to measure anesthesiologists' perceived intubation difficulty, ${ }^{18,22,23}$ and one study found a positive correlation between VAS score in difficulty of intubation and duration of intubation for indirect laryngoscopies. ${ }^{24}$ The absolute difference in mean VAS scores in difficulty of intubation in our study was small $(18 \mathrm{~mm})$, but the magnitude of difference needed to be considered clinically significant is unclear and likely context-specific. Nevertheless, any gap in perceived difficulty is likely to worsen in a time-pressed, less-than-ideal situation, such as intubating a SARS-CoV-2-positive patient in a remote location by a novice airway provider, who may be simultaneously burdened with human factor issues.
Cognitive load is likely to increase with the presence of a barrier enclosure during an unexpected difficult airway; for instance, the tracheas of two patients in the study group could not be intubated without removing the device.

There are a number of limitations in our study. First, the low-risk setting and population, combined with an experienced airway provider likely contributed to us finding no difference in the primary outcome. At the time of our study design, early data from mannequin studies 9 indicated a longer time to intubation using a barrier enclosure, making it ethically difficult to impose a randomized design on high-risk patients and on the anesthesiologists performing the intubation. We thus included only low-risk patients but ensured sufficient 
Table 1 Characteristics of patients randomized to barrier enclosure or control and intubating anesthesiologists

\begin{tabular}{lll}
\hline Characteristic & $\begin{array}{l}\text { Barrier enclosure } \\
N=48\end{array}$ & Control \\
& & 46 \\
Patients & $51(14)$ & $50(15)$ \\
Age (yr), mean (SD) & $20 / 48(42 \%)$ & $17 / 46(37 \%)$ \\
Female, $n /$ total (\%) & $169(12)$ & $71(11)$ \\
Height (cm), mean (SD) & $73(14)$ & $26(5)$ \\
Weight (kg), mean (SD) & $26(4)$ & $2[1-2]$ \\
BMI (kg-m ${ }^{-2}$ ), mean (SD) & $2[1-2]$ & $2[1-2]$ \\
ASA physical status, median [IQR] & $2[1-2]$ & $6.1(0.9)$ \\
Mallampati score, median [IQR] & $6.4(0.5)$ & $5.4(1.2)$ \\
Thyromental distance (cm), mean (SD) & $5.6(1.0)$ & $1[1-1]$ \\
Inter-incisor distance (cm), mean (SD) & $1[1-1]$ & \\
Upper lip bite test grade, median [IQR] & & $40(7)$ \\
Anesthesiologists & $40(7)$ & $29 / 46(63)$ \\
Age (yr), mean (SD) & $30 / 48(63)$ & $5[1-9]$ \\
Female, $n / t o t a l ~(\%)$ & $4[1-10]$ & \\
Years of practice, median [IQR] &
\end{tabular}

ASA = American Society of Anesthesiologists; IQR = interquartile range; SD = standard deviation

Table 2 Intraoperative variables

\begin{tabular}{lll}
\hline & $\begin{array}{l}\text { Barrier enclosure } \\
N=48\end{array}$ & $N=46$ \\
\hline Time to rocuronium administration (sec), mean (SD) & $217(83)$ & $214(70)$ \\
Last recorded $\mathrm{ETO}_{2}$ before paralysis (\%), mean (SD) & $84(7)$ & $85(5)$ \\
$\mathrm{ETO}_{2}$ immediately post-intubation (\%), mean (SD) & $81(7)$ & $81(7)$ \\
Number of attempts, median [IQR] & $1[1-1]$ & $1[1-1]$ \\
Cormack-Lehane view, median [IQR] & $1[1-2]$ & $1[1-1]$ \\
\hline
\end{tabular}

$\mathrm{ETO}_{2}=$ end-tidal oxygen concentration; $\mathrm{IQR}=$ interquartile range; $\mathrm{SD}=$ standard deviation

power in our sample size calculation and selected secondary endpoints that may signal potential issues even in low-risk patients to help inform the design of any future studies on a higher risk population. Second, the actual experience of the anesthesiologists with the McGrath videolaryngoscope may be a confounder. While we did attempt to collect information by asking anesthesiologists to record how many prior intubations they had performed with the McGrath videolaryngoscope, it relied on recollections and an accurate measure of actual experience was not performed. Nevertheless, the impact this variable has on the results is likely small and in part mitigated through randomization and having a minimum number of intubations required with and without barrier enclosure using the McGrath videolaryngoscope as necessary inclusion criteria. Third, the sample size required to detect a true difference between groups is probably much larger. Our sample size calculation was based on the SD of $10.5 \mathrm{sec}$ from a prior study examining the duration of intubation performed by consultant anesthesiologists using the McGrath blade without a barrier enclosure. ${ }^{19}$ With the barrier enclosure in this 


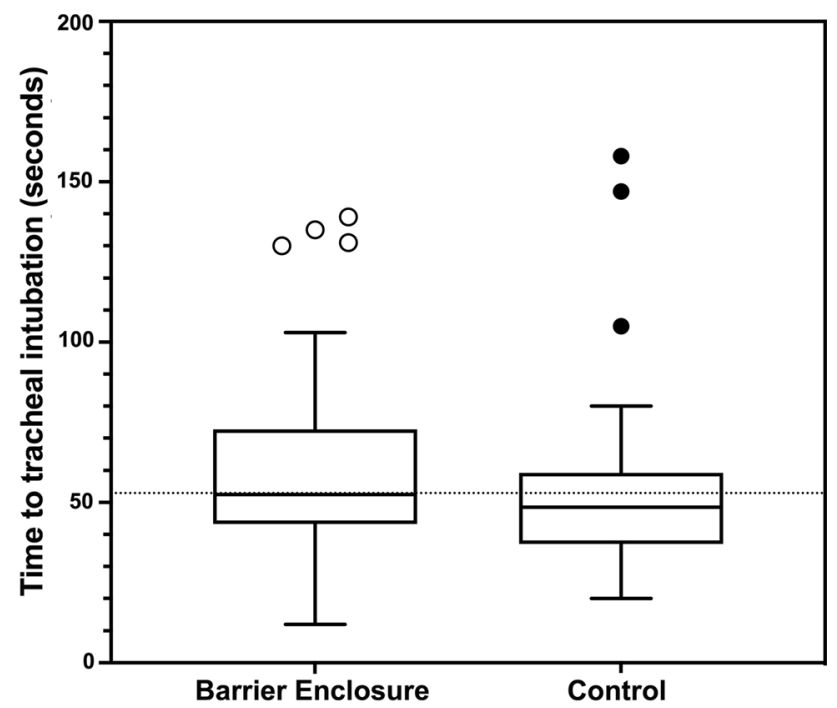

Fig. 2 Boxplots of time to tracheal intubation for barrier enclosure and control groups. The solid horizontal lines indicate the medians, the boxes extend to the IQR, the whiskers extend up to 1.5 times the IQR and the outliers beyond are indicated by hollow and solid circles. $\mathrm{IQR}=$ interquartile range

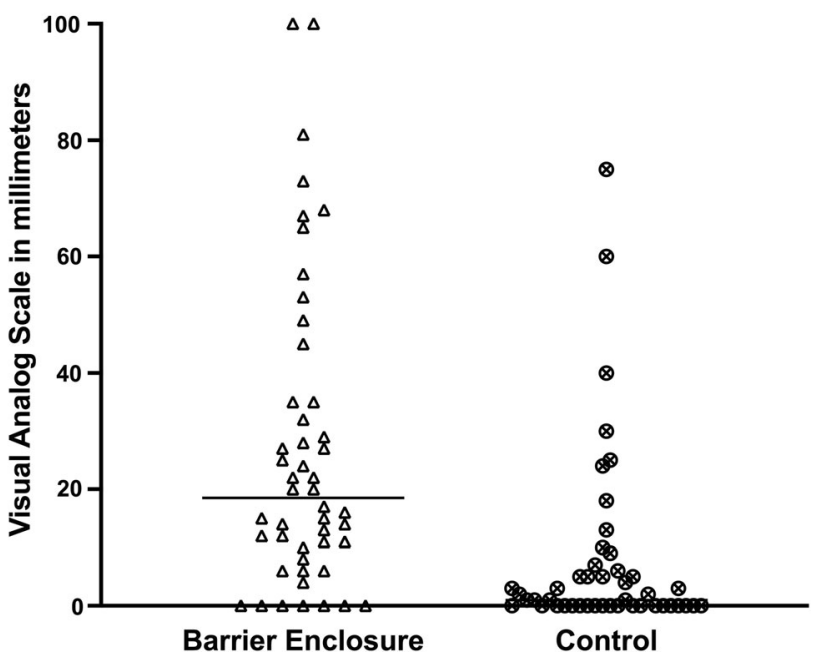

Fig. 3 Anesthesiologists' perception of intubation difficulty on a 0-100-mm visual analogue scale. Each marking represents a response; the solid line indicates mean

study, we observed a much wider $\mathrm{SD}$, at $29 \mathrm{sec}$. Using this value, a post hoc sample size calculation indicates that a total of 350 patients (175 per group) would be required to have $80 \%$ power to find a difference of $8.6 \mathrm{sec}$ between groups. This difference, however, likely has little clinical significance in our study population even if a statistical difference was shown. Finally, while our study provides insights into potential patient safety concerns regarding the clinical use of the barrier enclosure box, we did not study the efficacy of barrier enclosure in reducing viral transmission by preventing droplets and aerosols.

Guideline recommendations on the use of novel devices must weigh their intended benefits with potential risks. ${ }^{8}$ Efficacy data available thus far have been conflicting; certain barrier enclosure designs have actually been shown to promote an increase in aerosol exposure to the laryngoscopist through the arm holes. ${ }^{25-27}$ Proper safety studies, conducted with a discrete group of airway providers experienced in the use of barrier enclosure in altered contexts, are also lacking. ${ }^{6}$ The lack of firm efficacy and safety data led the U.S. Food and Drug Administration to revoke its authorization of the emergency use of COVID-19 barrier enclosures on 22 August $2020{ }^{8}$ Nevertheless, based on our personal experience, we wonder if the real-world utility of these devices lies in its use during extubation as opposed to intubation. Further efficacy and safety studies are needed to confirm or refute this idea.

If warranted, future adoptions or development of any intubation barrier enclosures require additional considerations for storage logistics, as well as material selection for durability and cost-effectiveness. In this study, three boxes were broken because they fell to the floor after being poorly stored in a high-traffic area (Fig. 4A). An additional box was broken secondary to repetitive use causing small fissures at high-stress junctions (Figure 4B). These experiences show the importance of rigorous regulatory frameworks in medical device development and the potential concerns in any self-made novel medical equipment. ${ }^{6}$

In conclusion, we found that, in healthy surgical patients with normal airway predictors, intubating with a MacGrath videolaryngoscope with a barrier enclosure extended the mean time to successful tracheal intubation by $8.6 \mathrm{sec}$ compared with no barrier enclosure, but this difference did not reach statistical significance. Nevertheless, there was a significant increase in intubation difficulty perceived by the anesthesiologists when a barrier enclosure was used raising a potential patient safety concern. 
Table 3 Primary and secondary outcomes

\begin{tabular}{|c|c|c|c|}
\hline & $\begin{array}{l}\text { Barrier } \\
\text { enclosure } \\
N=48\end{array}$ & $\begin{array}{l}\text { Control } \\
N=46\end{array}$ & $P$ value \\
\hline \multicolumn{4}{|l|}{ Primary outcome } \\
\hline Time to tracheal intubation $(\mathrm{sec})$, mean $(\mathrm{SD})^{*}$ & $62(29)$ & $53(27)$ & 0.14 \\
\hline \multicolumn{4}{|l|}{ Secondary outcomes } \\
\hline Total time of airway manipulation $(\mathrm{sec})$, mean $(\mathrm{SD}) \dagger$ & $73(29)$ & $68(34)$ & 0.42 \\
\hline Proportion of first-pass successful intubation, n/total (\%) & $43 / 48(90)$ & $\begin{array}{r}43 / 46 \\
(93)\end{array}$ & 0.71 \\
\hline Anesthesiologists' perception of intubation difficulty on 100-mm VAS (mm), mean (SD) & $27(26)$ & $9(17)$ & $<0.001$ \\
\hline $\begin{array}{l}\text { Anesthesiologists' likelihood of using barrier enclosure on SARS-CoV-2-positive patients, median } \\
\text { [IQR }] \text { t }\end{array}$ & $3[2-4]$ & $2[2-3]$ & 0.11 \\
\hline Patient perception of comfort of barrier enclosure, median $[\mathrm{IQR}] \S$ & $1[1-3]$ & - & - \\
\hline Patient perception of acceptability of barrier enclosure, median [IQR]\| & $1[1-3]$ & - & - \\
\hline
\end{tabular}

* Time from passage of the laryngoscope blade through lips to first upstroke of capnograph trace

$\dagger$ Time from lifting of face mask seal to first upstroke of capnograph trace

\$Five-point Likert scale: 1 = Highly likely, 2 = Likely, $3=$ Neutral, $4=$ Unlikely, 5 = Highly unlikely

§Five-point Likert scale: 1 = Completely comfortable, $2=$ Comfortable, $3=$ Neutral, $4=$ Uncomfortable, $5=$ Completely uncomfortable

|Five-point Likert scale: 1 = Completely acceptable, $2=$ Acceptable, $3=$ Neutral, $4=$ Unacceptable, $5=$ Completely unacceptable

$\mathrm{IQR}=$ interquartile range; $\mathrm{SD}=$ standard deviation; VAS = visual analogue scale

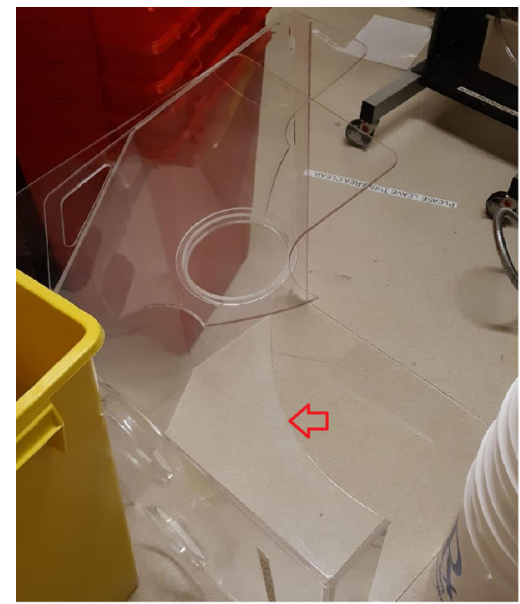

(A)

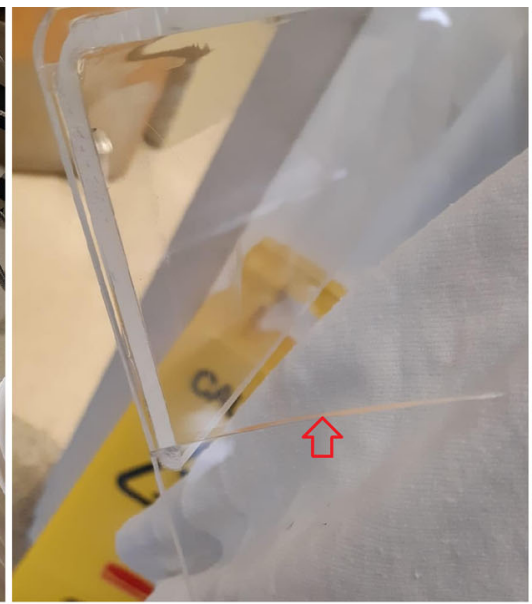

(B)

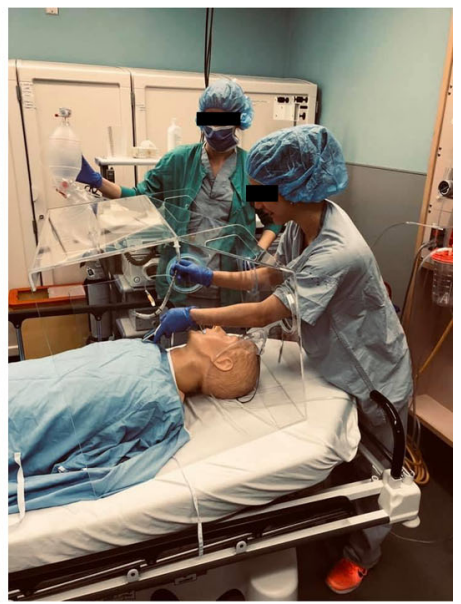

(C)

Fig. 4 COVID-19 barrier box broken during storage or transport because of (A) falling to the floor or (B) repetitive use resulting in small fractures at points of stress. (C) Final box design being used in a simulated intubation 
Author contributions Tim Ting Han Jen contributed to the conception of study idea and design; data acquisition, analysis, and interpretation; and writing and revision of the manuscript. Vionarica Gusti contributed to the data acquisition and entry and writing of the manuscript. Charanjit Badh contributed to conception of study idea; data and equipment acquisition; and writing of the manuscript. Sachin Mehta contributed to data acquisition and writing of the manuscript. Justine Denomme contributed to the data acquisition and data entry. Shannon Lockhart contributed to the data acquisition. Benajir Shams contributed to the data acquisition and data entry. Beau Klaibert contributed to the data acquisition. Anthony Chau contributed to conception of study idea and design; data acquisition, analysis, and interpretation; and writing of the manuscript.

Acknowledgements We would like to thank all the surgical and operating room members of Providence Health Care for their support in conducting this study.

\section{Disclosures None.}

Funding statement No external funding. Departmental funding was received.

Editorial responsibility This submission was handled by Dr. Sheila Riazi, Associate Editor, Canadian Journal of Anesthesia/Journal canadien d'anesthésie.

\section{References}

1. World Health Organization. Weekly Epidemiological Update. Available from URL: https://www.who.int/publications/m/item/ weekly-operational-update-on-covid-19-19-april-2021 (accessed April 2021).

2. Wilson NM, Norton A, Young FP, Collins DW. Airborne transmission of severe acute respiratory syndrome coronavirus2 to healthcare workers: a narrative review. Anaesthesia 2020; 75: 1086-95.

3. Jayaweera $M$, Perera $H$, Gunawardana B, Manatunge $J$. Transmission of COVID-19 virus by droplets and aerosols: a critical review on the unresolved dichotomy. Environ Res 2020. DOI: https://doi.org/10.1016/j.envres.2020.109819.

4. Dhillon RS, Rowin WA, Humphries RS, et al. Aerosolisation during tracheal intubation and extubation in an operating theatre setting. Anaesthesia 2021; 76: 182-8.

5. Lockhart SL, Duggan LV, Wax RS, Saad S, Grocott HP. Personal protective equipment (PPE) for both anesthesiologists and other airway managers: principles and practice during the COVID-19 pandemic. Can J Anesth 2020; 67: 1005-15.

6. Turner MC, Duggan LV, Glezerson BA, Marshall SD. Thinking outside the (acrylic) box: a framework for the local use of custom-made medical devices. Anaesthesia 2020; 75: 1566-9.

7. Canelli R, Connor CW, Gonzalez, M, Nozari A, Ortega R. Barrier enclosure during endotracheal intubation. N Engl J Med 2020; 382: $1957-8$.

8. Mariano ER, Kou A, Stiegler MA, Matava C. The rise and fall of the COVID-19 aerosol box through the lens of Twitter. J Clin Anesth 2020. DOI: https://doi.org/10.1016/j.jclinane.2020. 110145 .

9. Begley JL, Lavery KE, Nickson CP, Brewster DJ. The aerosol box for intubation in coronavirus disease 2019 patients: an in-situ simulation crossover study. Anaesthesia 2020; 75: 1014-21.
10. Fong $S, L i E$, Violato E, Reid A, Gu Y. Impact of aerosol box on intubation during COVID-19: a simulation study of normal and difficult airways. Can J Anesth 2021; 68: 496-504.

11. Maharaj CH, O'Croinin D, Curley G, Harte BH, Laffey JG. A comparison of tracheal intubation using the Airtraq or the Macintosh laryngoscope in routine airway management: a randomised, controlled clinical trial. Anaesthesia 2006; 61: 1093-9.

12. Joshi R, Hypes $C D$, Greenberg J, et al. Difficult airway characteristics associated with first-attempt failure at intubation using video laryngoscopy in the intensive care unit. Ann Am Thorac Soc 2017; 14: 368-75.

13. Government of Canada. Hard-surface disinfectants and hand sanitizers (COVID-19): List of disinfectants with evidence for use against COVID-19. Available from URL: https://www. canada.ca/en/health-canada/services/drugs-health-products/ disinfectants/covid-19/list.html\#tbl1 (accessed April 2021).

14. Savoldelli GL, Schiffer E, Abegg C, Baeriswyl V, Clergue F, Waeber JL. Learning curves of the Glidescope, the McGrath and the Airtraq laryngoscopes: a manikin study: Eur J Anaesthesiol 2009; 26: 554-8.

15. Wallace CD, Foulds LT, McLeod GA, Younger RA, McGuire BE. A comparison of the ease of tracheal intubation using a McGrath MAC ${ }^{\circledR}$ laryngoscope and a standard Macintosh laryngoscope. Anaesthesia 2015; 70: 1281-5.

16. Nouruzi-Sedeh P, Schumann M, Groeben H. Laryngoscopy via Macintosh blade versus GlideScope: success rate and time for endotracheal intubation in untrained medical personnel. Anesthesiology 2009; 110: 32-7.

17. Cook TM, El-Boghdadly K, McGuire B, McNarry AF, Patel A, Higgs $A$. Consensus guidelines for managing the airway in patients with COVID-19: guidelines from the Difficult Airway Society, the Association of Anesthesiologists the Intensive Care Society, the Faculty of Intensive Care Medicine and the Royal College of Anaesthetists. Anaesthesia 2020; 75: 785-99.

18. Jones PM, Armstrong KP, Armstrong PM, et al. A comparison of glidescope videolaryngoscopy to direct laryngoscopy for nasotracheal intubation. Anesth Analg 2008; 107: 144-8.

19. Yao WL, Wan $L, X u H$, et al. A comparison of the McGrath ${ }^{\circledR}$ Series 5 videolaryngoscope and Macintosh laryngoscope for double-lumen tracheal tube placement in patients with a good glottic view at direct laryngoscopy. Anaesthesi. 2015; 70: 810-7.

20. Trujillo A, Arango $F$. Impact of aerosol box use on orotracheal intubation times in children. Pediatr Anesth 2021; 31: 237-8.

21. Madabhushi P, Kinthala S, Ankam A, Chopra N, Porter BR. Time to adapt in the pandemic era: a prospective randomized non inferiority study comparing time to intubate with and without the barrier box. BMC Anesthesiol 2020. DOI: https://doi.org/10. 1186/s12871-020-01149-w.

22. Biro P, Fried E, Schlaepfer M, Kristensen MS. A new retrograde transillumination technique for videolaryngoscopic tracheal intubation. Anaesthesia 2018; 73: 474-9.

23. Alhomary $M$, Ramadan E, Curran $E$, Walsh SR. Videolaryngoscopy vs. fibreoptic bronchoscopy for awake tracheal intubation: a systematic review and meta-analysis. Anaesthesia 2018; 73: 1151-61.

24. McElwain J, Simpkin A, Newell J, Laffey JG. Determination of the utility of the Intubation Difficulty Scale for use with indirect laryngoscopes. Anaesthesia 2011; 66: 1127-33.

25. Simpson JP, Wong DN, Verco L, Carter R, Dzidowski M, Chan $P Y$. Measurement of airborne particle exposure during simulated tracheal intubation using various proposed aerosol containment devices during the COVID-19 pandemic. Anaesthesia 2020; 75: 1587-95. 
26. Fidler RL, Niedek CR, Teng JJ, et al. Aerosol retention characteristics of barrier devices. Anesthesiology 2021; 134: 61-71.

27. Ibrahim $M$, Khan $E$, Babazade $R$, Simon $M$, Vadhera $R$. Comparison of the effectiveness of different barrier enclosure techniques in protection of healthcare workers during tracheal intubation and extubation. AA Pract 2020. DOI: https://doi.org/ 10.1213/XAA.0000000000001252.

Publisher's Note Springer Nature remains neutral with regard to jurisdictional claims in published maps and institutional affiliations. 